\title{
SLIDING MODE TORQUE CONTROL OF AN IPMSM AS INFLUENCED BY IRON LOSS
}

\author{
A. M. El-Sawy, Y. S. Mohamed, A. A. Hassan, and E. G. \\ Shehata \\ Electrical Eng. Dept., Faculty of Engineering, El -Minia Uni., Egypt \\ Sawy1980@yahoo.com
}

(Received December 24, 2010 Accepted January 16, 2011)

\begin{abstract}
This paper presents a robust direct torque control of an interior permanent magnet synchronous motor (IPMSM) based on a sliding mode controller. The sliding mode control (SMC) law is designed in such a way that the chattering effect is reduced and the problem of reaching phase stability is eliminated. A space vector modulation is combined with the SMC to ensure minimum ripple content and high resolution voltage control. To demonstrate the validity of the proposed scheme, the calculated motor speed, estimated motor torque, stator flux and stator current in the presence of iron losses are compared with those measured in the literature. It is concluded that consideration of iron losses in the dynamic model of the machine improves the theoretical predictions and reduces the discrepancies between the calculated and measured values.
\end{abstract}

Keywords: Dynamic model of an IPMSM taking iron losses into account- Direct torque control- Sliding mode control-Space vector modulation.

\section{INTRODUCTION}

Today, direct torque control (DTC) is one of the most applied techniques in the field of motor drives. The principle of the DTC is the direct selection of the inverter states based on the torque error, stator flux error, and stator flux angle [1-2]. Direct torque control has several advantages which can be summarized as fast transient response, simplicity, less parameters dependence, low switching frequency and absence of rotor position sensor. However, DTC has some drawbacks which degrades its performance. These drawbacks can be concluded as variable switching frequency, high torque and flux ripples, especially, at start and low speed operation [3-4].

Different techniques have been investigated in order to overcome these drawbacks and improve the DTC performance. Space vector modulation (SVM) is used in DTC of permanent magnet synchronous motor (PMSM) to fix the switching frequency and reduce the torque and flux ripples [5]. Instead of the switching table and hysteresis controllers, a proportional integral (PI) controller and reference flux vector calculator (RFVC) are used to determine the reference stator flux linkage vector [5]. The reference flux vector is produced according to the reference angular frequency of the stator flux linkage (the output of the PI torque regulator), the position of the estimated stator flux linkage and the amplitude of the reference flux linkage. Afterwards, the voltage space vectors and their duration are selected and calculated 
according to the error flux linkage vector, such that the error can be reduced to zero. In addition, a SVM is used to replace the switching table of the basic DTC. However, the switching frequency of the SVM is larger than that of the classical DTC, which in turn increases the switching losses. Discrete SVM has been employed in DTC of induction motor [6]. However, the motor speed signal was required. In [7], two triangular waveform generators, two comparators, and a PI controller are required to provide constant switching frequency. However, the proposed system was much complicated compared to the classical DTC. In [8], a root mean square torque ripple equation is derived for induction motor control. At each sample, an optimal switching instant which satisfy the minimum torque ripple was determined. However, the derived ripple equation was based on the motor parameters and the measured motor speed. Predictive DTC of PMSM is studied in [9]. The predictive torque and flux are used to select the suitable voltage vector and switching time for every sample. The time derivative of the torque, which required for predictive control, is based on the permanent magnet flux, and the rotor position. Intelligent controllers such as fuzzy or neuro-fuzzy controllers are used to solve the problems of DTC [10-14]. However, the complexity of these schemes is considered the main drawbacks.

Sliding mode control technique is an effective, high frequency switching control strategy for nonlinear systems with uncertainties. It offers many good properties such as good performance against unmodeled dynamics, insensitivity to parameters variation, external disturbance rejection and fast dynamic response. Sliding mode control has been proposed to improve the performance of classical DTC [15-19]. In [15], adaptive sliding mode torque controller is proposed for DTC of induction motor drive. However, all electric motor parameters and speed were required. In [16], cascade sliding mode controllers are proposed; one is used for regulating the motor speed and the other is dedicated for controlling the electromagnetic torque. In [17-18], three types of variable structure controller combined with space vector pulse width modulation are used to improve the performance of DTC of induction motor drives. However, large sliding mode gains were selected to obtain fast torque dynamic response which increases the chattering problem. In addition, the effect of load disturbance and parameters variation on the system performance was not studied. In [19], adaptive sliding mode controller is proposed for DTC of PMSM drive. However, the variable switching frequency problem was not overcome and the rotor position angle was required. In addition, the measured voltage and current signals were needed to be transformed the synchronous frame.

Many investigations about DTC of IPMSM drives were reported [1-14], but no attention was paid for the effect of iron loss on the drive performance.

In this paper, a novel direct torque control of an IPMSM drive system based on a robust sliding mode controller is presented to investigate how the system behavior is influenced by iron loss. The chattering phenomena and the reaching phase stability problems are taken into account in the design of SMC. A space vector modulation is combined with the SMC to ensure minimum ripple content and high resolution voltage control. To demonstrate the validity of the proposed scheme, the calculated motor speed, estimated torque, stator flux and stator current are compared with those measured previously [5]. It is found that consideration of iron losses results in improvement of the theoretical predictions of motor speed, estimated motor torque, stator flux and stator current when compared with the measured values. 


\section{DYNAMIC MODEL OF THE IPMSM}

The equivalent circuit of a PM synchronous motor based on a synchronous $\mathrm{d}-\mathrm{q}$ reference frame is shown in figure 1 . The effect of the iron losses is modeled by placing a parallel core loss resistance $\left(R_{i}\right)$ in both d and q equivalent circuit model [20]. From the equivalent circuit of figure 1, the dynamic motor model can be expressed as:

$V_{d}=R_{s} i_{d}+p \lambda_{d}-\omega_{e} \lambda_{q}$

$V_{q}=R_{s} i_{q}+p \lambda_{q}+\omega_{e} \lambda_{d}$

where $V_{d}$ and $V_{q}$ are the d-q axes terminal voltages components, $i_{d}$ and $i_{q}$ are the $\mathrm{d}-\mathrm{q}$ axes terminal currents components, $\lambda_{d}$ and $\lambda_{q}$ are the d-q axes stator flux linkages components, $\omega_{e}$ is the electric angular speed, $R_{s}$ is the stator circuit resistance, $L_{d}$ and $L_{q}$ are the $\mathrm{d}$ and $\mathrm{q}$ inductance components, and $p$ is the differential operator $\left(p=\frac{d}{d t}\right)$.

The stator flux linkage components can be written as:

$$
\begin{aligned}
& \lambda_{d}=L_{d} i_{d m}+\lambda_{f} \\
& \lambda_{q}=L_{q} i_{q m}
\end{aligned}
$$

where, $i_{d m}$ and $i_{q m}$ are the d-q magnetizing current components, and $\lambda_{f}$ is the permanent magnet flux.

The magnetizing currents components $\left(i_{d m}\right.$ and $i_{q m}$ ) are calculated from the difference between the line current components and the iron loss current components and can be expressed as:

$$
\begin{aligned}
& i_{d m}=i_{d}-i_{d i} \\
& i_{q m}=i_{q}-i_{q i}
\end{aligned}
$$

where, in steady state, the d-q iron loss currents components can be expressed as

$$
\begin{aligned}
& i_{d i}=-\frac{\omega_{e} \lambda_{q}}{R_{i}} \\
& i_{q i}=\frac{\omega_{e} \lambda_{d}}{R_{i}}
\end{aligned}
$$

The motor electromagnetic torque can be written in terms of the magnetizing current and flux linkage components as follows:

$T_{e}=1.5 P\left(\lambda_{d} i_{q m}-\lambda_{q} i_{d m}\right)$

where $P$ is the number of pole pairs. 
The mechanical equation of PM synchronous motor can be written as follows:

$$
p \omega_{r}=\frac{T_{e}-T_{L}-f_{d} \omega_{r}}{J}
$$

where $\omega_{r}$ is the mechanical angular speed, $T_{L}$ is the load torque, $J$ is the motor inertia, and $f_{d}$ is the frictional coefficient.

The stator flux linkage amplitude can be expressed as:

$\lambda=\left(\lambda_{d}^{2}+\lambda_{q}^{2}\right)^{0.5}$

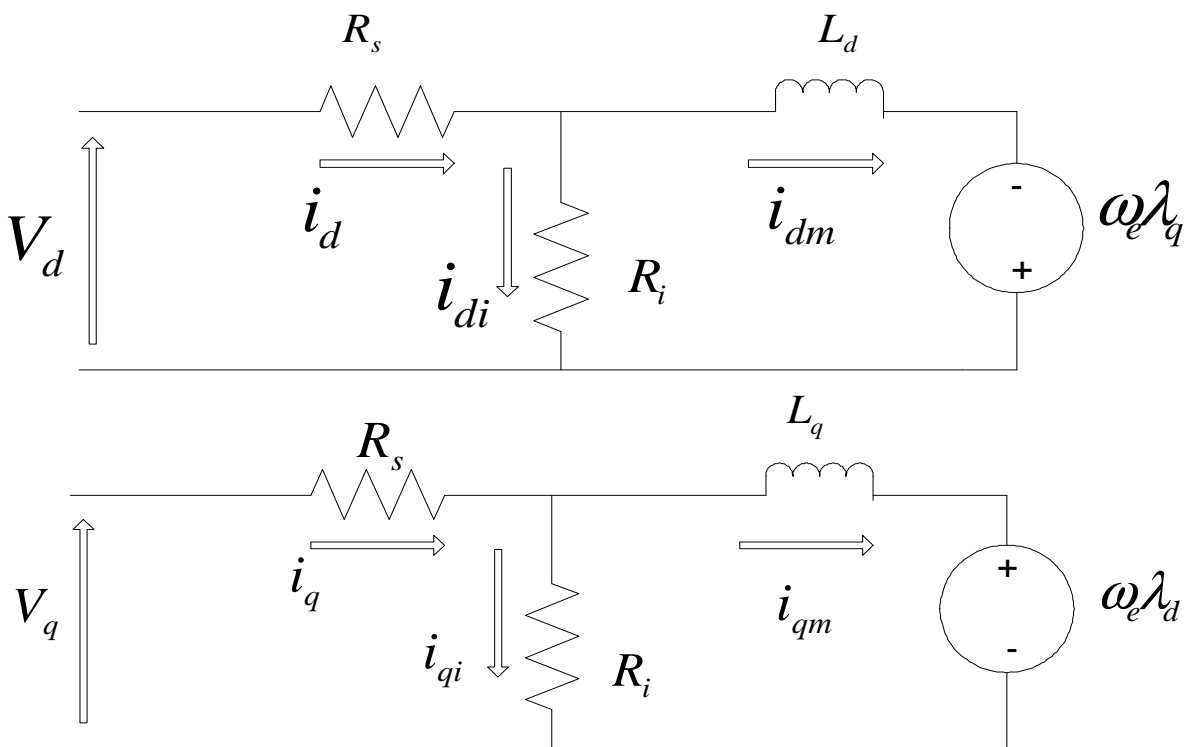

Figure 1: $\mathrm{d}$ and $\mathrm{q}$ axes equivalent circuits for IPMSM taking iron loss into account.

In the equivalent circuit, the iron loss per phase is modeled as

$$
P_{i}=R_{i}\left(i_{q i}^{2}+i_{d i}^{2}\right)
$$

The value of the core resistance can be modeled as a function of the operating frequency and the no-load core resistance $\left(R_{i o}\right)$. The core loss resistance $R_{i}$ is divided into two parallel resistances for hysteresis losses and eddy current losses, respectively. The hysteresis losses resistance $\left(R_{i h}\right)$ is proportional to the frequency and the eddy current resistance $\left(R_{i e}\right)$ does not depend on the frequency. Their expressions can be written as [21]

$$
\begin{aligned}
& R_{i h}=R_{\text {iho }}\left(\frac{\omega}{\omega_{b}}\right) \\
& R_{i e}=R_{\text {ieo }} \\
& R_{i}=R_{i e}+R_{i h}=R_{\text {ieo }}+R_{i h o}\left(\frac{\omega}{\omega_{b}}\right)
\end{aligned}
$$


where, $R_{\text {iho }}$ and $R_{\text {ieo }}$ are calculated at no-load condition at the rated operating frequency $\omega . \omega_{b}$ is the base frequency. The iron loss resistance at different speeds is drawn in figure 2 [21] and [22].

The (d-q) dynamic motor model in equations (1-2) can be expressed in the state space form as follows:

$$
\frac{d x}{d t}=f(x)+g(x) u
$$

where $x=\left[\begin{array}{ll}\lambda_{q} & \lambda_{d}\end{array}\right]^{T}$,

$$
\begin{array}{lll}
\text { where } & x=\left[\begin{array}{ll}
\lambda_{q} & \lambda_{d}
\end{array}\right]^{T}, & u=\left[\begin{array}{ll}
V_{q} & V_{d}
\end{array}\right]^{T}, \\
g(x)=\left[\begin{array}{ll}
1 & 0 \\
0 & 1
\end{array}\right], & \text { and } & f(x)=\left[\begin{array}{c}
f_{1} \\
f_{2}
\end{array}\right]=\left[\begin{array}{l}
-R_{s} i_{q}-\omega_{e} \lambda_{d} \\
-R_{s} i_{d}+\omega_{e} \lambda_{q}
\end{array}\right]
\end{array}
$$

\section{DIRECT TORQUE CONTROL PRINCIPLE OF THE IPMSM}

For IPMSM, the steady state electromagnetic torque equation can be written in terms of the load angle $(\delta)$ as follows [1-2]:

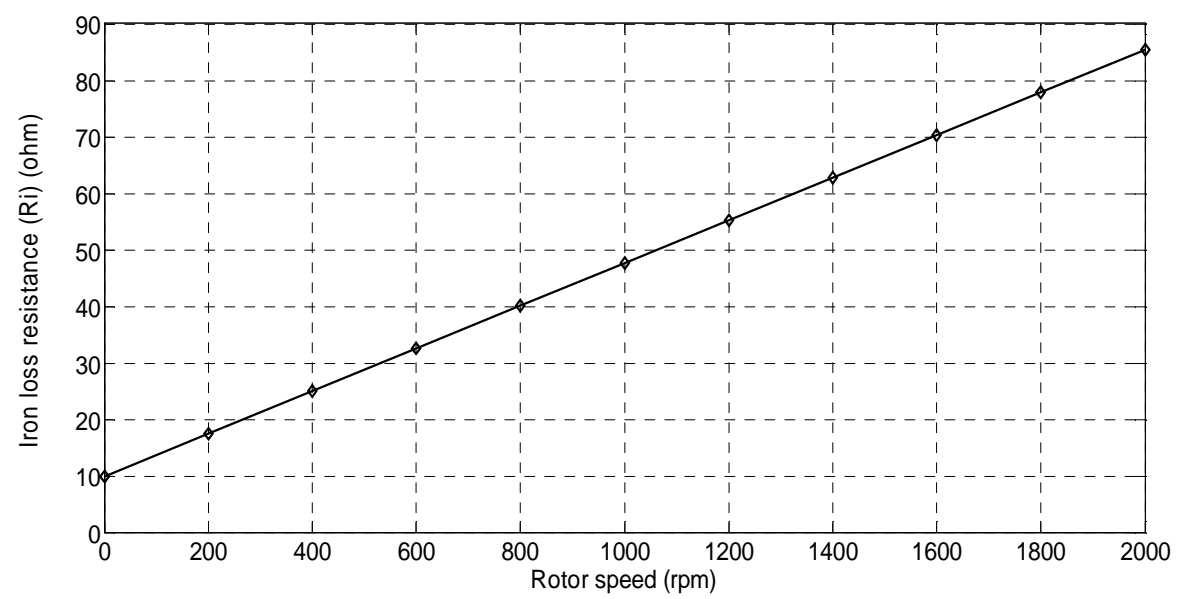

Figure 2: Variation of iron loss resistance with operating frequency.

$$
T(\delta)=\frac{3 P|\lambda|}{4 L_{d} L_{q}}\left[2 \lambda_{f} L_{q} \sin (\delta)-|\lambda|\left(L_{q}-L_{d}\right) \sin (2 \delta)\right]
$$

For constant stator flux amplitude, the torque can be controlled by regulating the load angle $(\delta)$. In other words, the torque can be regulated by controlling the stator flux speed with respect to the rotor speed. The stator flux vector components are estimated in the stationary reference frame $(\alpha-\beta)$ axes from the integration of the stator back emf using stator voltage and current measurements as follows:

$\hat{\lambda}_{\alpha}=\int\left(v_{\alpha}-R_{s} i_{\alpha}\right) d t+\lambda_{\alpha}(0)$ 


$$
\begin{aligned}
& \hat{\lambda}_{\beta}=\int\left(v_{\beta}-R_{s} i_{\beta}\right) d t+\lambda_{\beta}(0) \\
& \hat{\lambda}=\left(\hat{\lambda}_{\alpha}{ }^{2}+\hat{\lambda}_{\beta}{ }^{2}\right)^{0.5}
\end{aligned}
$$

where $\lambda_{\alpha}(0)$ and $\lambda_{\beta}(0)$ are the initial values of $\lambda_{\alpha}$ and $\lambda_{\beta}$, respectively. as follows:

The stator flux angle can be estimated from estimated stator flux components

$$
\hat{\theta}=\tan ^{-1}\left(\frac{\hat{\lambda}_{\alpha}}{\hat{\lambda}_{\beta}}\right)
$$

The electromagnetic torque can be estimated using the stator current and the estimated stator flux components as:

$$
\hat{T}=1.5 P\left(i_{\beta} \hat{\lambda}_{\alpha}-i_{\alpha} \hat{\lambda}_{\beta}\right)
$$

In the classical DTC, the errors between the reference and the estimated values of torque and flux are fed to two band hysteresis comparators to give digital outputs. The outputs of the hysteresis controllers and the stator flux position angle are fed to the lookup table which selects the switching procedure based on the inverter states. The torque and flux ripples are large, especially, at low speed operation [1-2]. In addition, the switching frequency depends on the hysteresis comparators band and the flux angle.

\section{DESIGN OF PROPOSED SMC FOR CONTROLLING TORQUE AND FLUX}

In the proposed algorithm, the torque PI controller and a reference flux vector calculator (RFVC) are replaced by the sliding mode controller. The sliding mode strategy is based on the design of the discontinuous control signal that drives the system states toward special manifolds in state space. These manifolds are chosen in such a way that the system will have the desired behavior as the state converges to them. The objective of the DTC is achieved by controlling the voltage input to the motor. The SMC is designed to generate the stator voltage reference from the errors between the estimated torque and flux and their references. Two integral switching functions $\left(s_{T}\right.$ and $\left.s_{\lambda}\right)$ are used for torque and flux control. These two switching functions determine the sliding surfaces. The stator voltage reference is generated based on these functions. The switching functions are based on the torque and flux errors and are selected as:

$$
\begin{aligned}
& s_{T}=K_{P s} e_{T}+K_{I s} \int_{0}^{t} e_{T} d t-e_{T}(0) \\
& s_{\lambda}=K_{P s} e_{\lambda}+K_{I s} \int_{0}^{t} e_{\lambda} d t-e_{\lambda}(0)
\end{aligned}
$$

where 


$$
\begin{aligned}
& e_{T}=T^{*}-\hat{T} \\
& e_{\lambda}=\lambda^{*}-\hat{\lambda}
\end{aligned}
$$

$K_{P S}$ and $K_{I s}$ are positive gains. $T^{*}$ and $\lambda^{*}$ are torque and flux reference values, respectively. The and $e_{T}(0)$ and $e_{\lambda}(0)$ are the initial values of the torque and flux errors.

The task is to design a control law to drive the state trajectory to the intersection of the surfaces described earlier. By differentiating (23) and (24), these yield

$$
\begin{aligned}
& \dot{s}_{T}=K_{P s} \dot{e}_{T}+K_{I s} e_{T} \\
& \dot{s}_{\lambda}=K_{P s} \dot{e}_{\lambda}+K_{I s} e_{\lambda}
\end{aligned}
$$

Using equations (1,2, and 16), the derivative of the stator flux and torque can be obtained as follows:

$$
\begin{aligned}
& \dot{\hat{\lambda}}=\frac{1}{\hat{\lambda}}\left(\lambda_{d} f_{1}+\lambda_{q} f_{2}\right)+\frac{1}{\hat{\lambda}}\left(\lambda_{d} V_{d}+\lambda_{q} V_{q}\right) \\
& \dot{\hat{T}}=1.5 P\left[L \lambda_{q} f_{1}+\left(L \lambda_{d}+\frac{\lambda_{f}}{L_{d}}\right) f_{2}+L \lambda_{q} V_{d}+\left(L \lambda_{d}+\frac{\lambda_{f}}{L_{q}}\right) V_{q}\right]
\end{aligned}
$$

where $L=\frac{1}{L_{q}}-\frac{1}{L_{d}}$

From equations (16), and (27-30), the derivative of the switching function can be written in the following form:

$$
\dot{s}=M+F-D u
$$

where

$$
\begin{aligned}
& \dot{s}=\left[\begin{array}{l}
\dot{s}_{T} \\
\dot{s}_{\lambda}
\end{array}\right], \\
& M=\left[\begin{array}{l}
M_{1} \\
M_{2}
\end{array}\right]=\left[\begin{array}{l}
K_{I s} e_{T}+K_{P s} \dot{T}^{*} \\
K_{I s} e_{\lambda}+K_{P s} \dot{\lambda}^{*}
\end{array}\right], \\
& F=\left[\begin{array}{c}
-1.5 P K_{P s}\left(L \lambda_{q} f_{1}+\left(L \lambda_{d}+\frac{\lambda_{f}}{L_{d}}\right)\right) f_{2} \\
-\frac{K_{P s}}{\hat{\lambda}}\left(\lambda_{d} f_{1}+\lambda_{q} f_{2}\right)
\end{array}\right] \\
& D=\left[\begin{array}{cc}
1.5 P K_{P s}\left(L \lambda_{d}+\frac{\lambda_{f}}{L_{q}}\right) & 1.5 P K_{P s} L \lambda_{q} \\
\frac{K_{I s}}{\hat{\lambda}} \lambda_{q} & \frac{K_{I s}}{\hat{\lambda}} \lambda_{d}
\end{array}\right]
\end{aligned}
$$


The system uncertainties occur due to the deviation of the motor parameters from their nominal values and an external load disturbance may occur. Equation (31) can be modified as:

$$
\dot{s}=M+F_{n}-D_{n} u+W
$$

where $D_{n}$ and $F_{n}$ are the nominal values of $D$ and $F$ and $W$ is the lumped uncertainty which can be given as:

$$
W=\left[\begin{array}{l}
W_{T} \\
W_{\lambda}
\end{array}\right]=\Delta F+\Delta D u
$$

The control effort law of SMC is the reference stator voltage and can be selected to satisfy this condition $\dot{S}=0$, this yield :

$$
u^{*}=D_{n}^{-1}\left(M+F_{n}+\alpha \operatorname{sign}(s)\right)
$$

where $u^{*}=\left[\begin{array}{ll}V_{q}^{*} & V_{d}^{*}\end{array}\right]^{T}$,

$$
\alpha=\left[\begin{array}{cc}
\alpha_{T} & 0 \\
0 & \alpha_{\phi}
\end{array}\right]
$$

where $\alpha_{T}$ and $\alpha_{\phi}$ are arbitrary positive gains.

The stability of the proposed SMC is proved using Laypounve's stability theorem and is listed in Appendix I [15].

The stator flux and the torque of the motor can be regulated by the stator voltage components. The highly nonlinear and coupled dynamics of the matrices $\left(D_{n}^{-1}\right.$ and $F_{n}$ ) complicate the design of the SMC. However, if the estimated stator flux amplitude is controlled to be constant and track its reference, the variables of these matrices $\left(D_{n}^{-1}\right.$ and $\left.F_{n}\right)$ can be analyzed as bounded disturbances. So, it can be added to the lumped uncertainties. The control effort equation can be written as follows:

$V^{*}=M+\alpha_{1} \operatorname{sign}(s)$

Where $\alpha_{1}>\left|W+D_{n}{ }^{-1} F_{n}\right|$

The control effort is designed in equation (41) such that the system trajectory is forced towards the sliding surface $S=0$. However, this control strategy produces some drawbacks associated with large control chattering that may wear coupled mechanisms and excite unstable system dynamics. In addition, the sensitivity of the controlled system to uncertainties still exists in the reaching phase. The reaching phase is the time during which the system state trajectory reaches the sliding surface. The control effort of the total torque/ flux sliding mode controller can be written as [15] and [16]:

$V^{*}=M+\alpha s a t(s)+K_{c} s+\left[\begin{array}{l}K_{T} \hat{T} \\ K_{\phi} \hat{\lambda}\end{array}\right]$

Where $\quad$ sat $(S)=\frac{S}{|S|+\lambda}, \quad K_{T}, K_{\phi}$ and $K_{c}$ are arbitrary positive gains. 


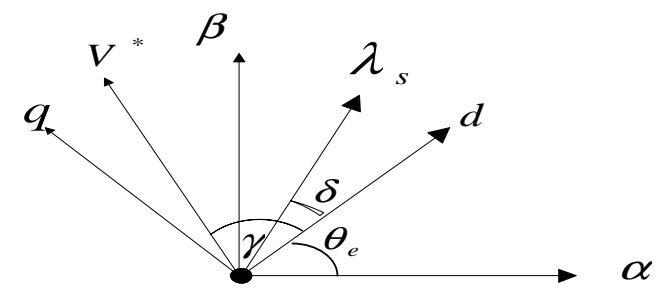

Figure 3: Space position of the stator voltage and flux vectors.

The function sat $(S)$ is used instead of the function sign $(S)$ to reduce the chattering in the control effort.

The reference stator voltage amplitude $\left(V^{*}\right)$ and its position $(\gamma)$ are estimated as:

$$
\begin{aligned}
& V^{*}=\left(V_{d}{ }^{* 2}+V_{q}{ }^{* 2}\right)^{0.5} \\
& \gamma=\tan ^{-1}\left(\frac{V_{q}{ }^{*}}{V_{d}{ }^{*}}\right)
\end{aligned}
$$

As shown in figure 3, the reference voltage position with respect to $\alpha$-axis in the stationary frame is expressed as:

$\theta^{*}=\gamma+\theta_{e}$

Where, $\theta_{e}$ is the rotor electric angular position angle.

\section{CONTROL SYSTEM BLOCK DIAGRAM}

Figure 4 shows the block diagram of the proposed DTC scheme. This figure shows that the SMC produces the stator reference voltage based on the torque and flux errors as inputs. The stator flux vector and the motor torque are estimated from the stator voltage and current measurements. No additional measurements or axis transformation are required. In this scheme, space vector modulation is used to generate the inverter switching states with constant switching frequency by using the stator voltage reference and the rotor angular position. In a conventional DTC, a single voltage vector is applied during each sample period. On the other hand when SVM is used, this makes six voltage vectors applied during each sample. The number of switching states is increased, and in turn, the motor torque and flux ripples are decreased. Thus, the SVM provides high resolution voltage output. The output voltage of the inverter is used as an input data to the IPMSM model where the iron loss is considered. For speed control based DTC, a proportional- integral (PI) controller is used to develop the torque reference required for the SMC. The rotor position angle $\left(\theta_{e}\right)$ is estimated from the integration of the measured speed. The gains of the speed controller are used in this control scheme are obtained using common synthesis method [22]. 


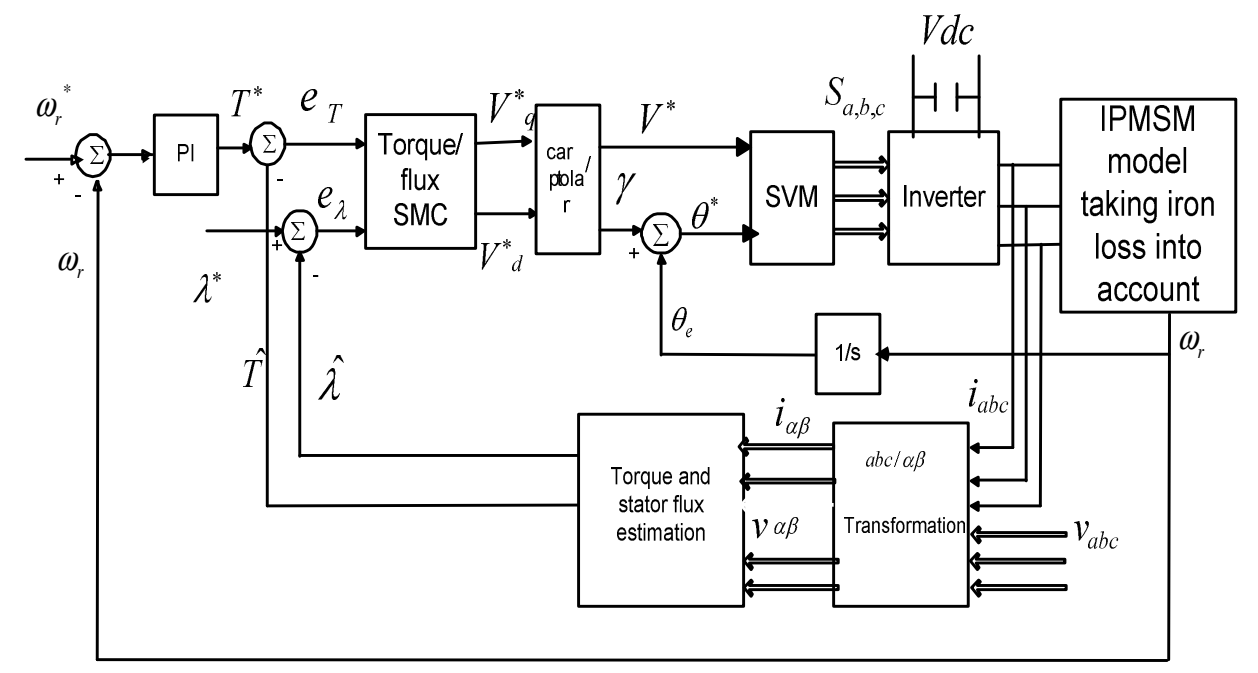

Figure 4: Block diagram of the proposed torque / flux SMC controller for IPMSM scheme.

\section{RESULTS AND DISCUSSION}

In order to verify the validity and the performance of the proposed scheme of figure 4, digital simulations are carried out using MATLB software to investigate how the performance of the proposed system is influenced by iron loss. The stator flux reference $\left(\lambda^{*}\right)$ is set equal to $0.55 \mathrm{Web}$., and the switching frequency of the proposed algorithm (SMC-SVM) is chosen $6 \mathrm{kHz}$. The different values of arbitrary positive gains of the proposed algorithm are tuned to give satisfactory performance. The nominal parameters and data specifications of the IPMSM used for simulation are listed in Appendix II.

Firstly, the motor performance is investigated at constant speed and full load torque operation (about $80 \%$ of rated speed). Figures $5 \mathrm{a}$ and $5 \mathrm{~b}$ show the calculated and measured [5] motor speed, estimated torque and estimated stator flux linkage from top to bottom. The predicated motor speed values according to simulated model agree satisfactory with those measured experimentally. Also, consideration of iron loss in motor model is to bring the estimated torque and flux linkage values closer to those measurements experimentally. The measured speed and torque waveforms have ripples of amplitude $0.5 \mathrm{rpm}$ and $0.3 \mathrm{~N} . \mathrm{m}$, respectively, in comparison with those computed. Figures $6 \mathrm{a}$ and $6 \mathrm{~b}$ show the calculated phase current waveform and the measured one, respectively. The amplitude of the current agrees approximately with the measured one. However, there are some ripples in the measured phase current due to the motor space harmonics which is disregarded in the motor model. 

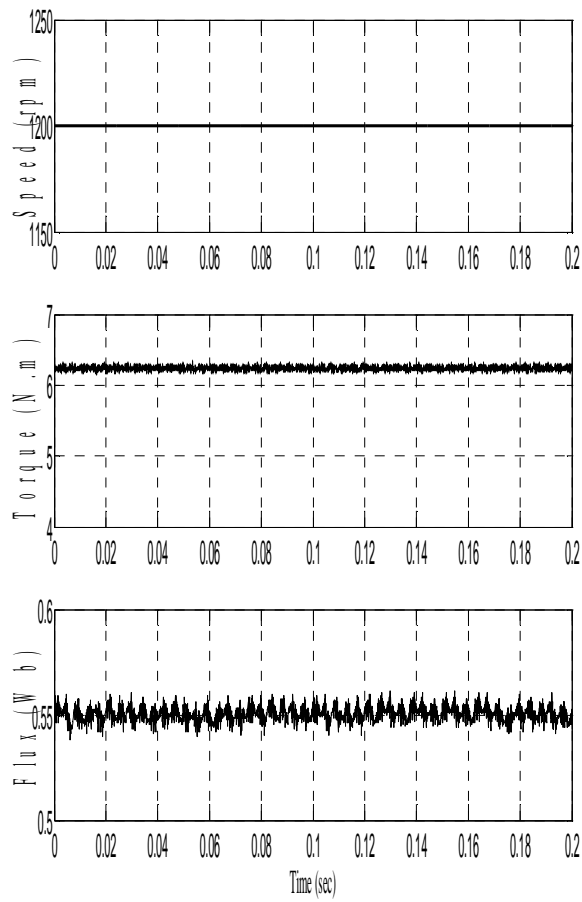

(a)
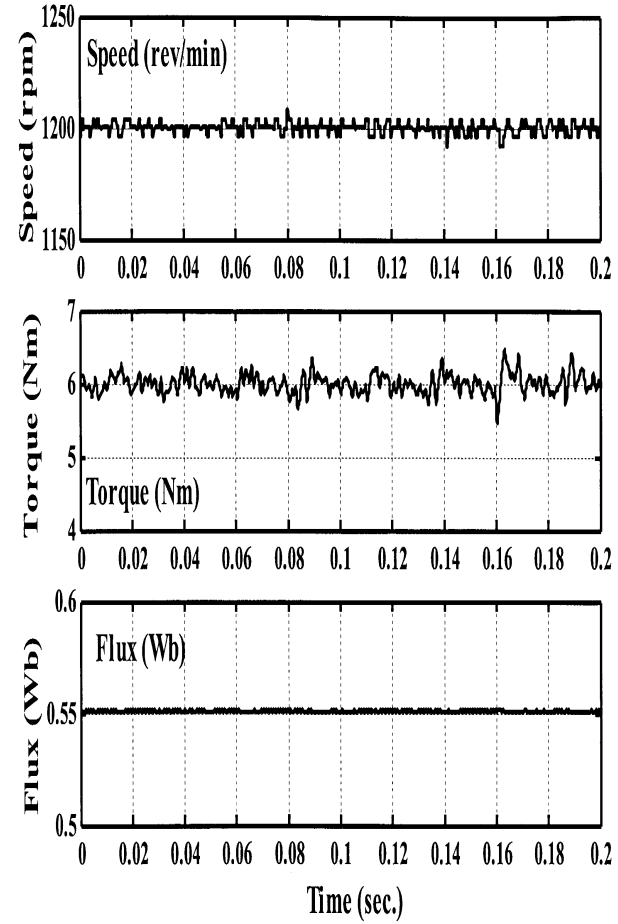

(b)

Figure 5: Speed, torque and flux at $1200 \mathrm{rev} / \mathrm{min}$ with full load for (a) the SMC-SVM (simulation) and (b) the DTC-SVM (measured)

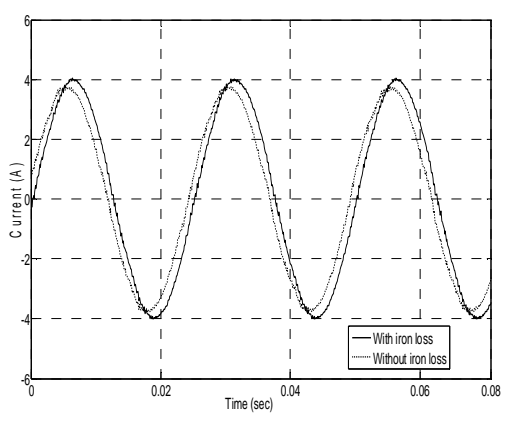

(a)

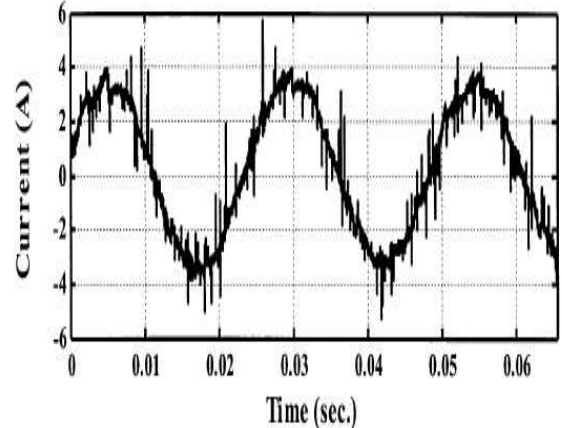

(b)

Figure 6: Current waveforms at $1200 \mathrm{rev} / \mathrm{min}$ with full load torque for (a) the SMC-SVM (simulation) and (b) the DTC-SVM (measured)

Secondly, the proposed scheme is tested at low speed operation and light load torque. The simulation results of the proposed scheme are obtained at $150 \mathrm{rpm}$ (10\% of its rated speed) and 1.1 N.m. Figure 7a shows the proposed computed values of motor speed, estimated torque and estimated stator flux linkage according to model taking iron loss into account. The effect of iron loss on estimated electromagnetic torque is small due to low fundamental frequency $(5 \mathrm{~Hz}$.). The calculated motor speed and torque 
of the proposed scheme show good agreement with those measured as shown in Figure 7b. The pervious algorithm can not operated stably blow this speed [5], while the proposed scheme can operate at zero and very low speeds. However, the estimated stator flux linkage of the proposed scheme contains ripples due to the chattering phenomena of the SMC.
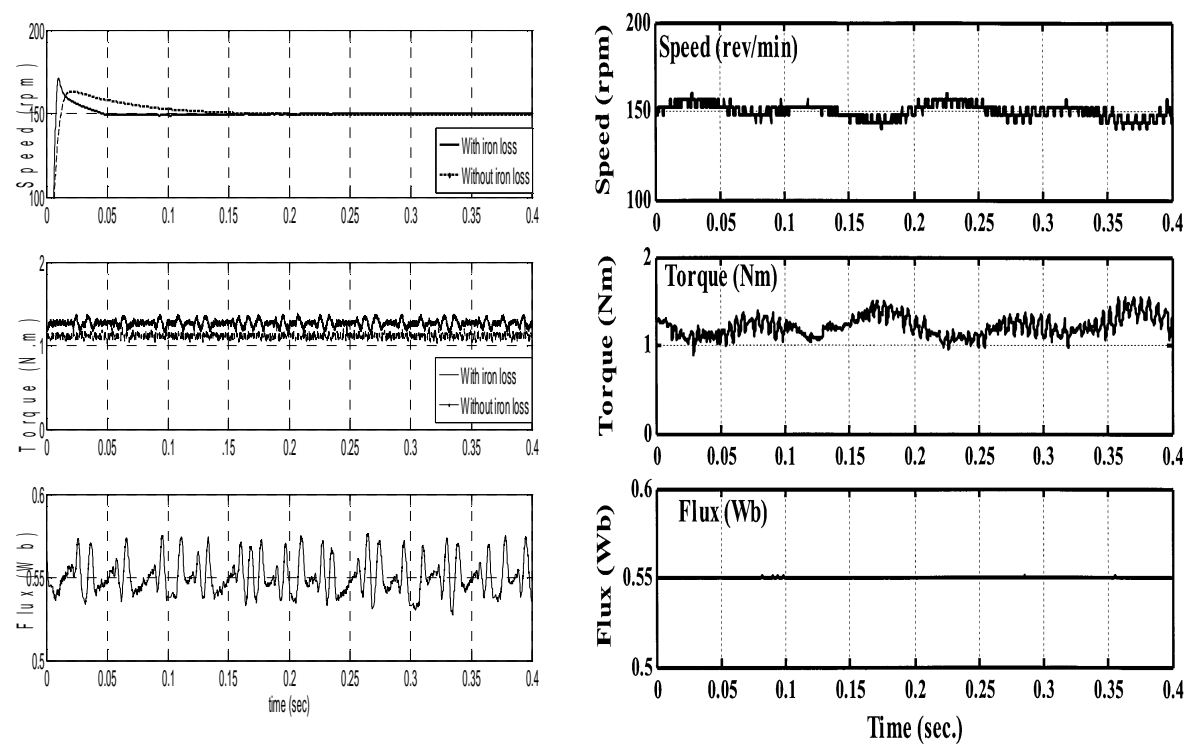

(a)

(b)

Figure 7: Speed, torque and flux at $150 \mathrm{rev} / \mathrm{min}$ with light load (1.1 N.m) for (a) the SMC-SVM (simulation) and (b) the DTC-SVM (measured)

Thirdly, the transient performance of the proposed scheme for step change of reference torque is investigated. Figure $8 \mathrm{a}$ and $8 \mathrm{~b}$ show the dynamic response of the estimated torque subjects to step change of reference torque from -2 to 6 N.m. These figures show that the predicted estimated motor torque values are close to those measured experimentally. A slight discrepancy between the transient response of the estimated motor torque values and their measured values are attributed to the mechanical loss which is not considered in the motor model. The results confirm that consideration of iron loss in the motor model improves the theoretical results.

Finally, the field weakening control combined with DTC is studied. The transient performance of the proposed scheme following to a large step change of speed reference for field weakening operation is also investigated. The nominal parameters and data specification of the IPMSM used for weakening operation are given in appendix III.

Figures 9a and 9b show the computed and measured [5] motor speed, estimated torque and estimated stator flux linkage from top to bottom. The predicated motor speed values are agreed satisfactory with those measured experimentally as shown in figure $9 \mathrm{a}$ and $9 \mathrm{~b}$. In addition, the predicted motor torque values are found to be close to those measured experimentally. The measured speed and torque ripples have high ripples in comparison with those proposed computed. However, the flux waveform has some ripples due to the chattering phenomena. 


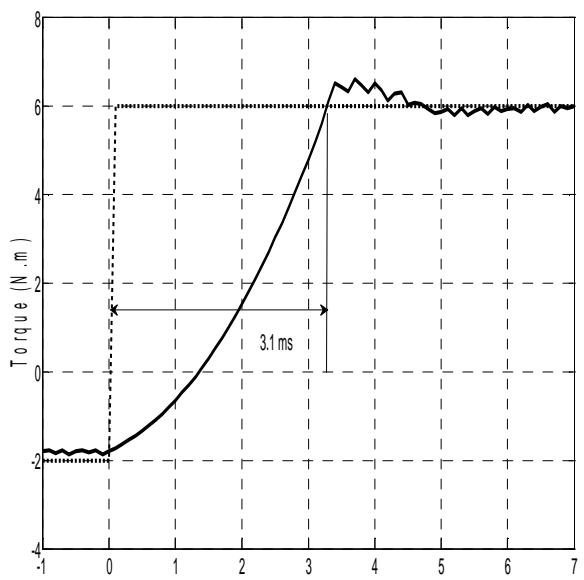

(a)

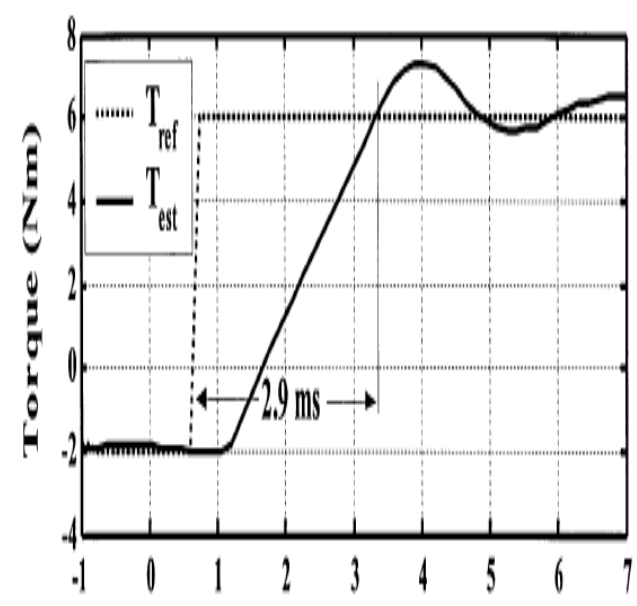

(b)

Figure 8: Dynamic response of the torque estimated for step change of load torque (a) the SMC-SVM (simulation) and (b) the DTC-SVM (measured)

\section{CONCLUSION}

In this paper, speed, torque and flux of IPMSM are controlled based on a direct torque control taking the effect of iron loss into account. A robust sliding mode controller with space vector modulation is proposed to improve the DTC performance. The calculated motor speed, estimated motor torque, stator flux and stator current of the proposed scheme are compared with those measured in the literature [5].
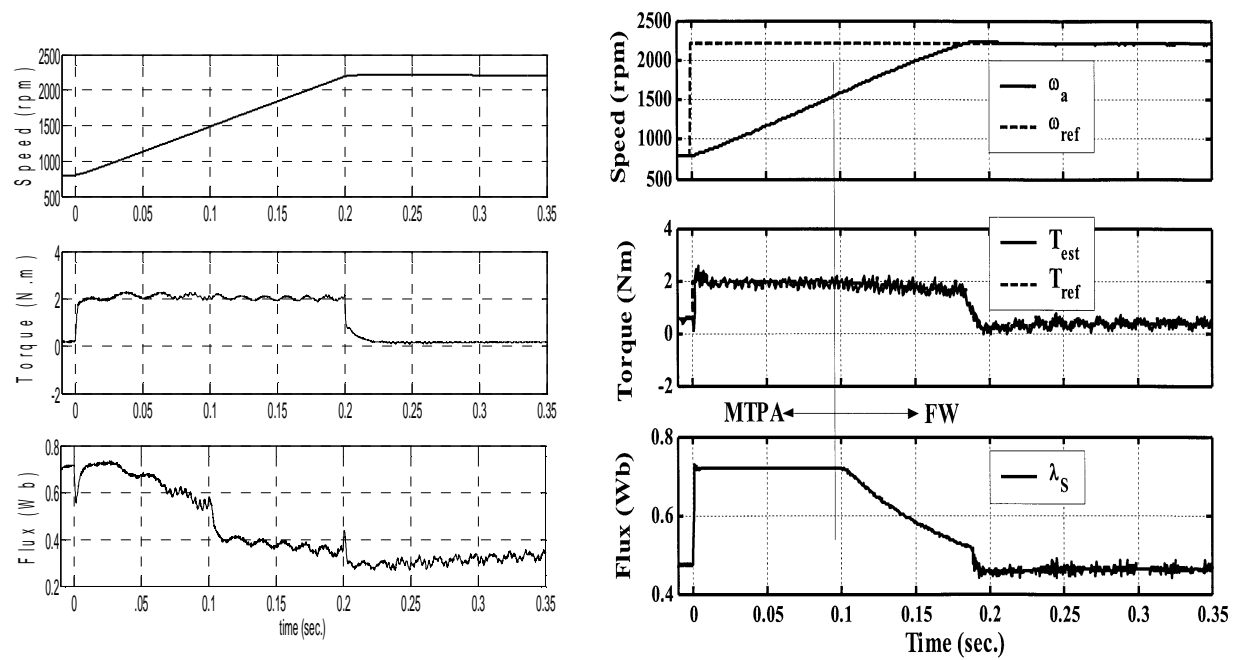

(a)

(b)

Figure 9: Speed, torque and flux waveforms under field weakening operation for (a) the SMC-SVM (simulation) and (b) the DTC-SVM (measured) 
In view of dynamic analysis and investigations presented, one can draw the following main conclusion:

1- The influence of the iron loss on performance of sliding mode direct torque control has been investigated at constant value of medium speed operation and full load torque. Consideration of iron loss in the motor model shows that the calculated motor speed, torque and stator flux values agreed satisfactory with those measured experimentally.

2- Consideration of iron loss into account when the motor operated at low speed and light load, the results of the calculated speed, torque and stator flux are found to be in a good agreement with those measured ones. However, the calculated stator flux linkage value has some ripples due to chattering phenomena.

3- The influence of the iron loss on the estimated torque response for step change of reference torque has been presented. The calculated torque values are found to be in close agreement with the measured experimentally. However, a slight deviation between the calculated values of motor torque and measured results are attributing to disregarding the mechanical motor loss in the motor model.

4- The field weakening control based DTC is proposed. Taking iron loss into account when the motor is subject to large step change of reference speed, calculated results are found to be in good agreement with those measured results.

This confirms that consideration of core loss in motor modeling improves the theoretical prediction and reduces the error between calculated and measured values.

\section{REFERENCES}

1. L. Zhong, M.F. Rahman, W.Y.Hu, K. W. Lim, and M.A. Rahman, "A Direct Torque Controller For Permanent Magnet Synchronous Motor Drives", IEEE Trans. On Energy Conversion, Vol. 14, No. 3, pp. 637-642,1999.

2. L. Zhong, M.F. Rahman,, K. W. Lim, and L.Zhong, "A Direct Torque Controlled Interior Permanent Magnet Synchronous Motor Drive Incorporating Field Weakening ", IEEE Trans. On Indust. Appl, Vol. 34, No.6, pp. 1246-1253, 1998.

3. Lixin Tang, M. F. Rahman, L. Zhong, , and M.E. Haque, "Problems Associated With The Direct Torque Control Permanent Magnet Synchronous Motor Drive And Their Remedies ", IEEE Trans. On Indust. Electronics, Vol. 51, No. 4, pp. 799-809, 2004.

4. Giuseppe S.Buja, and Marian P.Kazmierkowski," Direct Torque Control Of PWM Inverter- Fed Ac Machine- A Survey”, IEEE Trans. On Indust. Electronic, Vol. 51, No. 4, pp. 744-757, 2004.

5. Lixin Tang, M. F. Rahman, L. Zhong, , and Yuwn Hu, "A Novel Direct Torque Controlled Interior Permanent Magnet Synchronous Motor With Low Ripple In Flux And Torque And Constant Switching Frequency", IEEE Trans. On Energy Conversion, Vol. 19, No.2, pp. 346-354, 2004.

6. Xin Wei, Dayue Chen, and Chunyu Zhao, "Minimizing Of Torque Ripple Of Direct Torque Controlled Induction Machine By Improved Discrete Space Vector Modulation" Electric power systems research, Vol. 72, pp. 103-112, 2004.

7. Nik Rumzi Nik Idris, and A.H.Mahamed Yatim," Direct Torque Control Of Induction Motor With Constant Frequency Switching And Reduced Torque 
Ripple.” IEEE Trans. On Indust. Electronic, Vol. 51, No. 4, pp. 758-767, Aug 2004.

8. Jun-Koo Kang and Seung-Ki Sul, "New direct torque control of induction motor for minimum torque ripple and constant switching frequency," ", IEEE Trans. On Indust. Appl, Vol. 35, No. 5, pp. 1076-1081, 1999.

9. Mario Pacas, and Jurgen Weber, "Predictive Direct Torque Control for the PM Synchronous Machine” IEEE Trans. On Indust. Electronic, Vol. 52, No. 5, pp. 1350-1356, 2005.

10. Pawel Z. Grabowski, Marian P. Kazmierkowski, Bimal K. Bose and Frede Blaabjerg, "A simple direct torque neuro-fuzzy control of PWM-inverter-fed induction motor drive", IEEE Trans. On Indust. Electronic, Vol. 47, No. 4, pp. 863-869, 2000.

11. L. Romeral, A. Arias, E. Aldabas, and M. G. Jayne," Novel direct torque control (DTC) scheme with fuzzy adaptive torque ripple reduction", IEEE Trans. On Indust. Elect., Vol. 50, No. 3, June 2003, pp. 487-492.

12. M. Vasudevan and R. Arumugam, "High- performance adaptive intelligent direct torque control schemes for induction motor drives", KMITL, sci. Tech. J. Vol. 5, No. 3, 2005

13. Zhang Chunmei, Liu Heing, Chen Shujin, and Wang Fangjun, "Application of neural networks for permanent magnet synchronous motor direct torque control", Journal of systems engineering and electronics. Vol 19, No. 3 , pp. 555- 561, 2008.

14. Huang Yourui and Tang Chaoli, “ Direct torque control of induction motor by using of neural network", proceeding of the eighth international conference on Electric machine and system, Vol 3,pp 2415-2117, 2005.

15. Rong. Jong. Wai, "Adaptive sliding mode control for induction servomotor drive", IEE Pro.Power Appl.Vol.147. No.6, 2000.

16. A. A. Hassan, Y. S. Mohamed, and E. G. Shehata, "Cascade sliding mode torque control of a permanent magnet synchronous motor", IEEE international conference on industrial technology, ICIT, pp 465-470, 2006.

17. C. Lascu, I. Boldea, and F. Blaabjerg, " Direct torque control of sensorless induction motor drives: a sliding mode approach", IEEE Trans. On Indust. Electron., Vol. 40, No.2,pp. 582-590, 2004.

18. C. Lascu, I. Boldea, and F. Blaabjerg, "Variable -structure direct torque control A class of fast and robust controllers for induction motor drives", IEEE Trans. On Indust. Electron., Vol. 41, No.4, pp. 785-792, 2004.

19. C. H. Fang, C. M. Huang, and S. K. Lin, "Adaptive sliding mode torque control of a PM synchronous motor", IEE Proc.-Electro. Power Appl., Vol. 149, No. 3, pp. 228-236, 2002.

20. Naomitsu Urasaki, Tomonobu Senjyu, and Katsumi Uezato, "Relationship of Parallel Model and Series Model for Permanent Magnet Synchronous Motors Taking Iron Loss Into Account” IEEE Trans. On. Energy Convers., Vol. 19, NO. 2, pp. 265-270, June 2004

21. Y.-K. Chin, and J. Soulard, " Modeling of iron losses in permanent magnet synchronous motors with fields weakening capability for electric vehicles" International Journal of Automation Technology, Vol.4, No. 2, pp. 87-94, 2003.

22. K. Ogata, "Discrete Time Control System”, Second Ed., Prentice-Hall, 1995. 


\section{Appendix I}

The stability of the proposed SMC can be proved using Lyapunov stability theorem.

Defining Lyapunov function as follows:

$V=\frac{1}{2} s^{T} s$

The time derivative of $V$ on the state trajectory is given by

$\dot{V}=s^{T} \dot{s}$

Substituting equation (36) in equation (A.2), one can obtain:

$$
\begin{aligned}
& \dot{V}=s^{T}\left(M+F_{n}-D_{n} u+W\right) \\
& \dot{V}=s^{T} M+s^{T} F_{n}-s^{T} D_{n} u+s^{T} W
\end{aligned}
$$

Substituting the control effort from equation (38) into equation (A.4)

$$
\begin{aligned}
& \dot{V}=s^{T} M+s^{T} F_{n}+s^{T} W-s^{T} D_{n} D_{n}^{-1}\left(M+F n+\alpha \operatorname{sign}\left(s^{T}\right)\right) \\
& \left.=s^{T} M+s^{T} F_{n}+s^{T} W-s^{T} M-s^{T} F_{n}-s^{T} \alpha \operatorname{sign}\left(s^{T}\right)\right) \\
& \text { i.e } \quad \dot{V}=s^{T} W-\alpha\left|s^{T}\right|
\end{aligned}
$$

For $\alpha\rangle|W|$, equation (A.6) will ensure $\dot{V} \leq 0$

This proves the stability of the proposed scheme.

\section{Appendix II}

Table 1: Parameters and data specification of the IPMSM.

\begin{tabular}{|c|c|c|c|c|c|}
\hline $\begin{array}{c}\text { Phase } \\
\text { voltage }(\mathrm{V})\end{array}$ & $132 \mathrm{~V}$ & Rated power & $1000 \mathrm{~W}$ & Rated speed & $1500 \mathrm{rpm}$ \\
\hline $\mathrm{R}_{\mathrm{s}}$ & $5 \Omega$ & PM flux linkage $\left(\lambda_{f}\right)$ & $0.533 \mathrm{Web}$. & No. of poles & 4 \\
\hline $\mathrm{L}_{\mathrm{q}}$ & $102.7 \mathrm{mH}$ & $\mathrm{L}_{\mathrm{d}}$ & $44.8 \mathrm{mH}$ & Rated torque & 6 N.m \\
\hline
\end{tabular}

\section{Appendix III}

Table 2: Parameters and data of the IPMSM for field weakening operation.

\begin{tabular}{|c|c|c|c|c|c|}
\hline $\begin{array}{c}\text { Phase } \\
\text { voltage }(\mathrm{V})\end{array}$ & $240 \mathrm{~V}$ & Rated power & $500 \mathrm{~W}$ & Rated speed & $1500 \mathrm{rpm}$ \\
\hline $\mathrm{Rs}$ & $18.6 \Omega$ & PM flux linkage $\left(\lambda_{f}\right)$ & $0.447 \mathrm{Web}$ & No. of poles & 4 \\
\hline $\mathrm{Lq}$ & $475.5 \mathrm{mH}$ & $\mathrm{Ld}$ & $388.5 \mathrm{mH}$ & Rated torque & 1.9 N.m \\
\hline
\end{tabular}




\section{المتحكم الانزلاقى فى عزم المحرك التزامنى ذى الأقطاب المغناطيسية الدائمة تحت}

\section{تأثير الفقد فى الأجزاء الحديدية}

يدرس هذا البحث تحكم مباشر متين فى عزم محرك تزامنى ذو أقطاب مغناطيسية دائمة اعتمادا على المتحكم

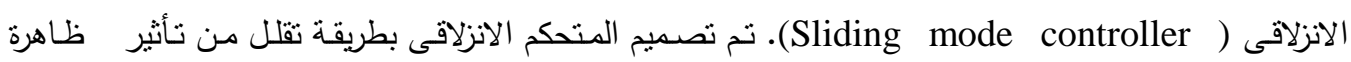

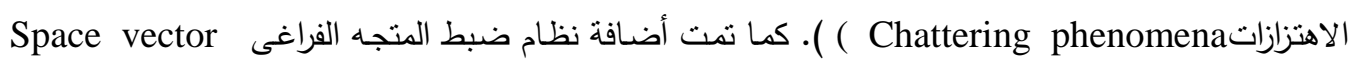
للحصول على أقل تموجات فى العزم و الفيض المغناطيسى للمحرك و زيادة نقاء الجهد. (modulation)

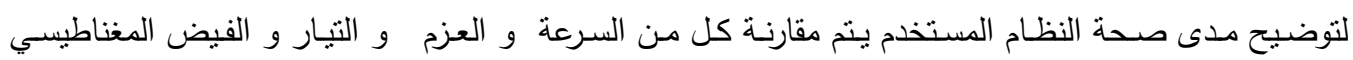

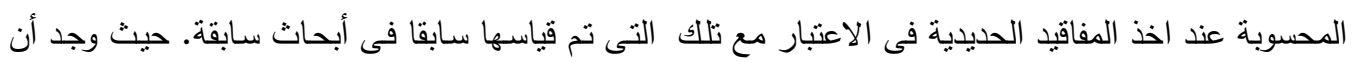

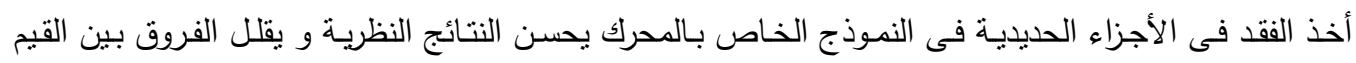

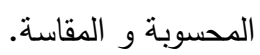

